\title{
Ärzte-Umfrage
}

\section{Note 4+ für den Pharma-Außendienst}

\author{
Viele Niedergelassene sind von Pharma-Referenten genervt - vor allem wenn diese unangemeldet in die \\ Praxis kommen. Was die Mediziner an den Außendienstlern noch stört und was sie sich von ihnen erhoffen, \\ zeigt die erste Auswertung einer großen Umfrage.
}

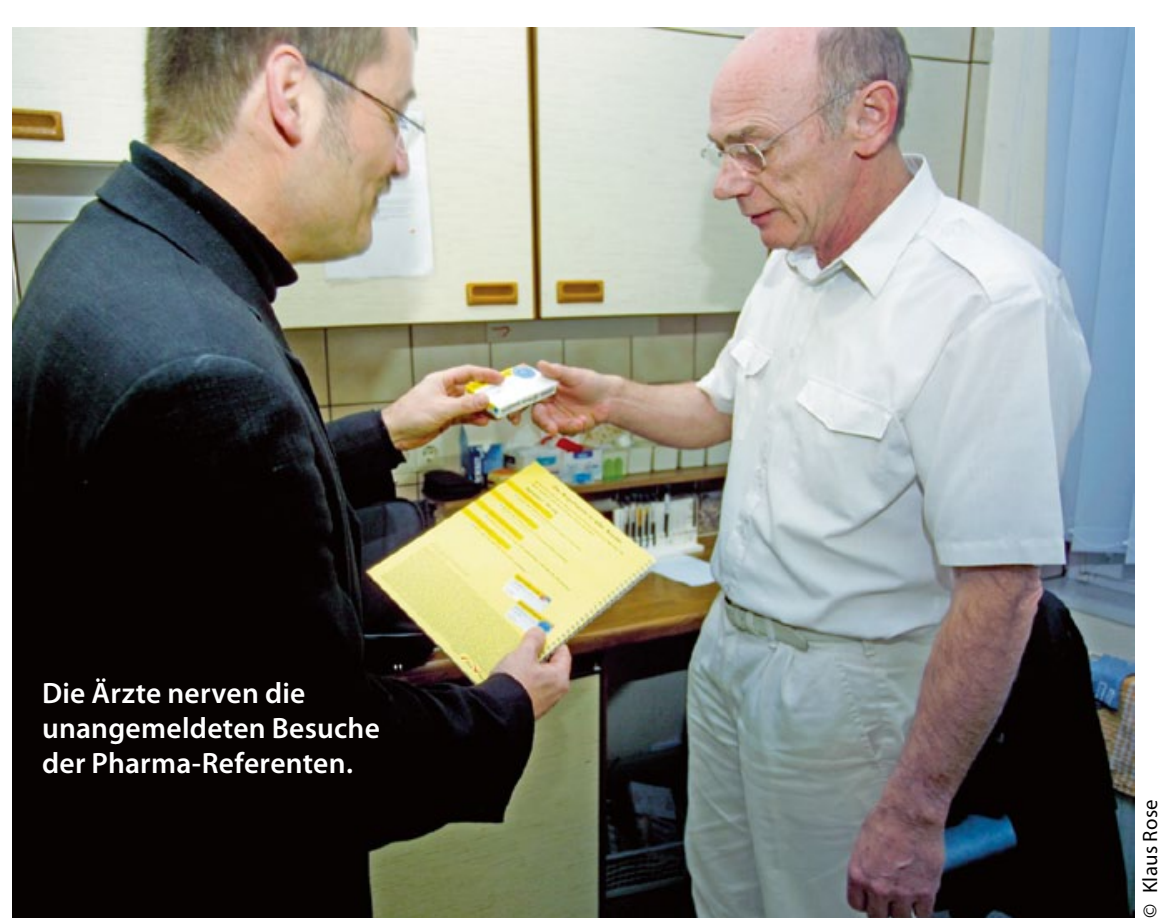

$\mathrm{V}$ iele niedergelassene Ärzte haben ein ambivalentes Verhältnis $\mathrm{zu}$ Pharma-Referenten, die ihre Praxis besuchen. Sie sind mit dem Angebot der Außendienst-Mitarbeiter an vielen Punkten unzufrieden, möchten aber auch nicht auf sie verzichten. Das zeigt ein aktuelles Projekt des Düsseldorfer Instituts für betriebswirtschaftliche Analysen, Beratung und Strategie-Entwicklung (IFABS). Das Institut hatte niedergelassenen Ärzten angeboten, mit einem „Pharma-QuickCheck“ die Qualität von Pharma-Referenten zu bewerten. Die Resonanz ist groß: Knapp 5.000 Ärzte haben sich inzwischen an der Erhebung beteiligt. „Wir haben offensichtlich einen Nerv getroffen“, sagt IFABSLeiter Klaus-Dieter Thill.

Auf der Schulnotenskala von 1 bis 6 erhalten die Pharma-Referenten im
Durchschnitt die Note 3,8. Die fünf von den Ärzten am häufigsten genannten Stärken sind der Erhebung zufolge sehr gute Fortbildungsangebote, Verständnis für die Situation der Ärzte, Freundlichkeit und Hilfsbereitschaft, persönliche Betreuung sowie kompetente Informationen, die über reine Produktaspekte hinausgehen.

\section{Unangemeldete Besuche nerven}

Als Schwächen des pharmazeutischen Außendienstes führen die Ärzte in der Befragung auf: zu häufige Besuche, Besuche ohne Anmeldung, die ständige Wiederholung gleicher Informationen, antrainierte Standard-Gespräche und unglaubwürdige Gesprächsunterlagen. Die unangemeldeten Besuche zur Kurzinformation über einzelne Präparate seien aus Sicht der niedergelassenen Ärzte das größte Ärgernis, berichtet Thill. „Sie bringen häufig den Praxisbetrieb durcheinander, führen zu Beschwerden von Patienten und haben auch inhaltlich keinen Wert." Die Erwartung der Praxisinhaber an die Außendienst-Mitarbeiter der Pharmaindustrie hat sich verschoben, sagt Thill. „Die Ärzte erwarten mehr als die reine Produktinformation." Das liege zum Teil daran, dass sich aufgrund der geringen Anzahl von Innovationen der Stellenwert dieses Aspekts verringert hat. Außerdem gingen die Ärzte zunehmend dazu über, sich die Informationen aus anderen Quellen zu holen.

\section{Thema Praxisführung kommt an}

Das IFABS hat die Ärzte auch gefragt, für wie ersetzbar sie die Präparateinformationen des Außendienstes halten. Dabei ergab sich ein Durchschnittswert von $78 \%$; $100 \%$ hätte ,vollständig ersetzbar" bedeutet. Laut der Erhebung entfällt beim Besuch der Pharma-Referenten im Durchschnitt nur noch knapp die Hälfte der Gesprächsdauer auf die produktbezogene Fachinformation.

Besonders gute Noten erhalten die Pharma-Referenten, die den Ärzten Hilfen bei der Praxisführung anbieten. Dabei geht es zum Beispiel um Fortbildungen für das Praxisteam oder um Unterstützung beim Praxismanagement, der Organisation oder dem Marketing. „Die Pharmaunternehmen müssen sich Gedanken darüber machen, wie das Leistungsspektrum der Außendienst-Mitarbeiter künftig aussehen soll“, folgert Thill aus den Ergebnissen.

Ilse Schlingensiepen 